\title{
Paradoxical Reaction of Acute Intestinal Occlusion in an Immunocompetent Patient: A Case Report in Benin
}

\author{
Attolou SGR ${ }^{1 *}$, Laleye $\mathrm{CM}^{1}$, Megninou MUB ${ }^{1}$, Yehouenou $\mathrm{CL}^{2}$, Takin $\mathrm{R}^{3}$, Mehinto DK ${ }^{1}$
}

${ }^{1}$ General Surgery Department, National University Hospital Hubert Koutoukou Maga of Cotonou (CNHU HKM)

${ }^{2}$ National and Teaching Hospital of Respiratory Diseases, National Reference Laboratory of Mycobacteria, Cotonou- Benin

${ }^{3}$ Adechina Histopathology Department, Cotonou- Benin

DOI: $10.36347 /$ sasjs.2021.v07i05.006

| Received: 07.04.2021 | Accepted: 12.05.2021 | Published: 22.05.2021

*Corresponding author: Attolou SGR

Abstract

Tuberculosis is a real public health problem. It is due to Mycobacterium tuberculosis, a bacterium with a strong pulmonary tropism. Extra-pulmonary forms represent $14 \%$ of all tuberculosis cases worldwide. Digestive damage represents $3 \%$ to $5 \%$. The treatment of tuberculosis is well codified these days. A paradoxical reaction (PR) to antituberculosis drugs is defined as worsening of pre-existing clinical or radiological lesions or the appearance of new lesions during anti-tuberculosis treatment. They are rarely described in the digestive system with an acute intestinal obstruction type. We report here a clinical case of a paradoxical reaction to the type of acute intestinal obstruction in an immunocompetent patient on anti-tuberculosis treatment. It was a 56-year-old male patient with no specific history, HIV-negative followed by pulmonology for bacteriologically confirmed pulmonary tuberculosis. He was put on Poly Chemotherapy (2ERHZ / 4RH). Progress under this treatment was marked by onset on day 35 of generalized abdominal pain associated with mechanical bowel obstruction with no fever. On admission to the surgical emergency room, besides abdominal pain, the patient presented bloating and bilious vomiting, abdominal meteorism and abdominal tympanism. The diagnosis of acute intestinal obstruction of the small intestine by obstruction of probable tuberculous etiology had been suggested and the patient operated on. During the operation, we had discovered dilated small intestine, multiple ileal and parieto-ileal adhesions with ileal strangulation $60 \mathrm{~cm}$ from the ileo-cecal junction, multiple granular micronodular lesions and mesenteric lymphadenopathy. Procudure included adhesions resection, biopsy of omentum and mesenteric lymphadenopathy The evolution was favorable and Histopathology analysis found images in favor of mycobacteriosis.

Key words: tuberculosis, paradoxical reaction, acute bowel obstruction.

Copyright $(\odot 2021$ The Author(s): This is an open-access article distributed under the terms of the Creative Commons Attribution 4.0 International License (CC BY-NC 4.0) which permits unrestricted use, distribution, and reproduction in any medium for non-commercial use provided the original author and source are credited.

\section{INTRODUCTION}

Tuberculosis remains a real public health problem, due to its high incidence; it is the ninth leading cause of death in the world, 1.4 million people died of tuberculosis around the world in 2019 [1]. It is due to Mycobacterium tuberculosis, a bacterium with a strong pulmonary tropism. According to WHO, extrapulmonary forms account for $14 \%$ of all tuberculosis cases worldwide [2]; intestinal involvement represents 3 to $5 \%$ [3]. Tuberculosis treatment is well known nowadays. Unusual evolution of tuberculosis under specific and well-managed treatment in patients not infected with HIV was first reported by Chloremis et al. in 1955 [4]. A paradoxical reaction (PR) to antituberculosis drugs is defined as worsening of preexisting clinical or radiological lesions or appearance of new lesions during anti-tuberculosis treatment [5]. These paradoxical reactions are less frequent in immunocompetent patients and in majority of cases involve the central nervous system, pleura and lungs [5]; they are rarely described in the digestive system such as acute intestinal obstruction [6]. We here-in report a case of paradoxical reaction revealed as acute intestinal obstruction in an immunocompetent patient on anti-tuberculosis treatment.

\section{CASE REPORT}

A 56-year-old male patient with no particular history, initially seen in pulmonology for chronic cough, with no notion of tuberculosis contagion. The onset of symptoms was 3 weeks prior to admission with cough and mucopurulent discharge without any notion of hemoptysis. Chest pain, dyspnea, fever, physical asthenia, non-selective anorexia, night sweats and weight loss amounting to $10 \%$ of body weight were associated with the cough. Note that the patient had negative HIV serology. 
The patient underwent a sputum examination (GeneXpert) which came back positive and diagnosis of bacteriologically confirmed Pulmonary Tuberculosis $(\mathrm{BPD}+)$ was confirmed. He was put on treatment (2ERHZ / 4RH). Progress under this treatment was marked by onset on day 35 of generalized abdominal pain associated with mechanical bowel obstruction with no fever necessitating his transfer to the surgical unit. On admission to the surgical emergency room, besides abdominal pain, the patient presented bloating and bilious vomiting.

Physical examination revealed an average general condition, moderately colored eyelid mucosa, normal vital signs, abdominal meteorism, abdominal tympanism with presence of hydroaeric sounds and an empty rectal ampulla on digital rectal examination. A plain abdominal $\mathrm{x}$-ray film shows hydroaeric images that are wider than high (image 1). Acute bowel obstruction diagnosis with probable tuberculosis etiology was suspected.

Preoperative assessement showed a slight hyponatremia at $134 \mathrm{mEq} / \mathrm{L}$. Patient was admitted to theatre after a brief preoperative resuscitation. Intraoperatively (image 2), there was presence of dilated small intestines up to about $60 \mathrm{~cm}$ from the ileo-cecal junction, the rest of the ileum and colon being normal, multiple ileal and parieto-ileal adhesions with ileal strangulation $60 \mathrm{~cm}$ from the ileo-cecal junction, multiple granular micronodular lesions spread over the entire small intestine as well as the omentum, the ascending mesocolon, mesenterium and mesenteric lymphadenopathy. Procudure included adhesions resection, biopsy of omentum and mesenteric lymphadenopathy, rincing and drainage of the peritoneal cavity, and parietal closure were performed. Post-operative course was uneventful with resumption of bowel function on the 4th postoperative day; abdominal drain was removed on the 4 th postoperative day. Resumption of anti-tuberculosis treatment on the 5 th postoperative day. The patient was released on the 8th postoperative day returning to pulmonology unit to continue his anti-tuberculosis treatment.

Histopathology analysis carried out on the biopsy specimens revealed on the lymphadenopathy, an altered eosinophilic necrosis, surrounded by numerous epithelioid cells without clear granulomas and on the omentum, epithelioid granulomas without necrosis. There was no gigantic cells. These results were in favor of a mycobacterial disease (Image 3). The patient was declared cured of tuberculosis five months later.

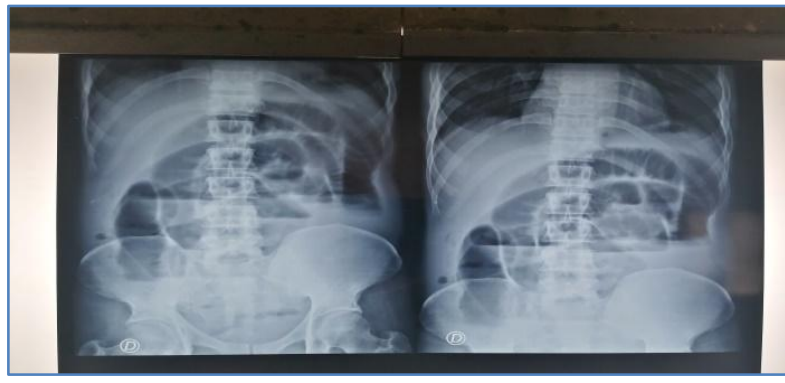

Fig-1: Plain Abdominal X-ray film

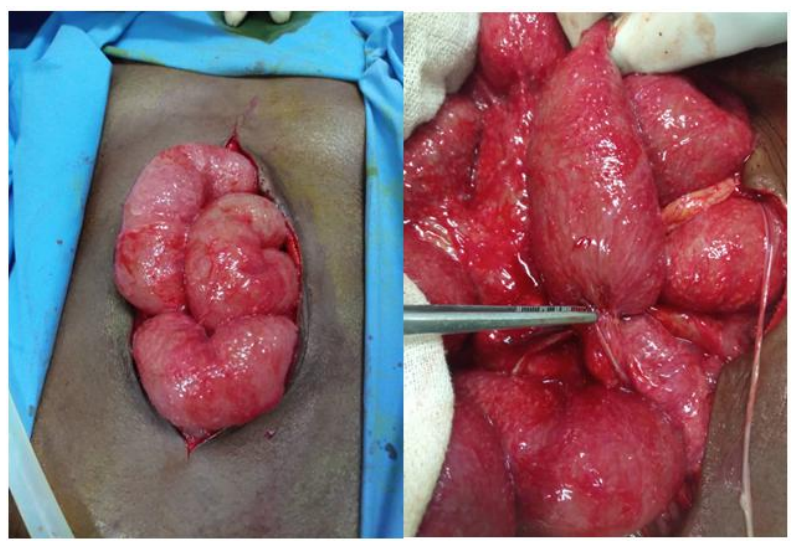

Fig-2: Peroperative findings

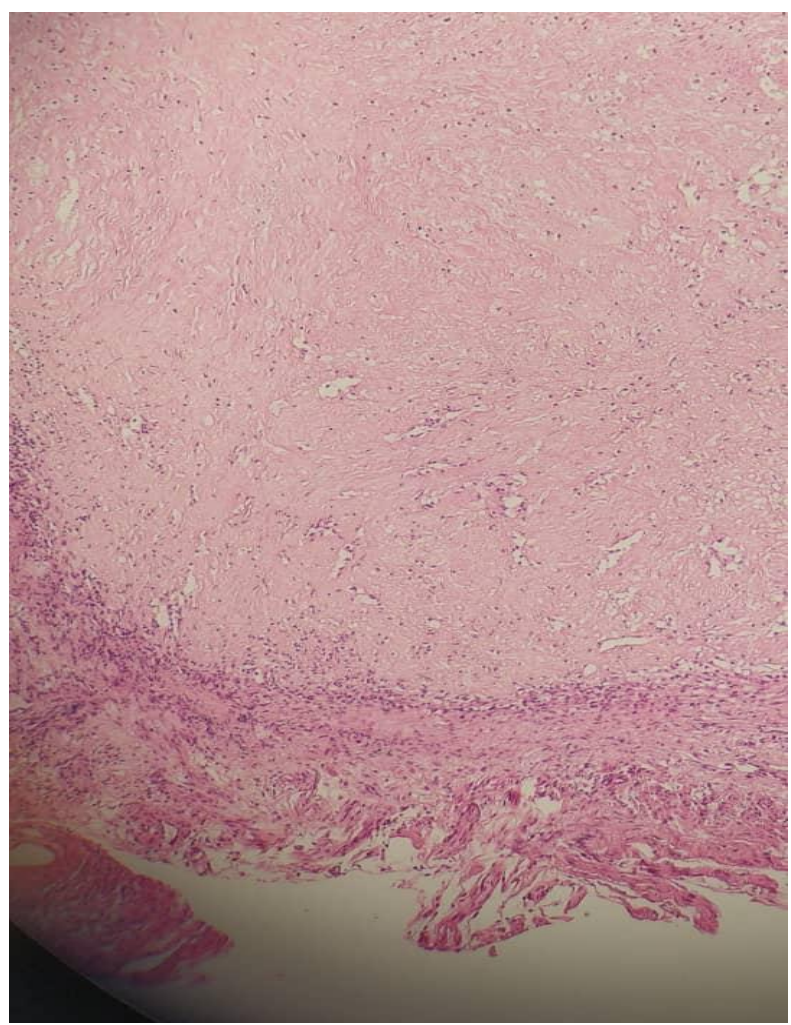

Fig-3: Microscopic lesions as seen on histopathology analysis

\section{DISCUSSION}

Tuberculosis remains a major public health problem in Benin. It mainly affects the most disadvantaged sections of the population [7]. In Benin, the number of new cases of extra-pulmonary 
tuberculosis increased from 318 in 2018 to 328 in 2019 [7]; the frequency of extra-pulmonary tuberculosis is $7.49 \%$ [7], well below the prevalence of 20 to $25 \%$ in regions according to WHO [8]. The abdomen is one of the most frequent sites of extra-pulmonary tuberculosis [9]; gastrointestinal tract is the sixth most frequent extra-pulmonary site, after the lymphatic system, genitourinary system, osteoarticular system, miliary involvement and the neuro-meningeal system [3]. A pulmonary site is associated in 20 to $25 \%$ of cases. In this case, digestive involvement is as much frequent and massive as the pulmonary involvement is severe [3, 9]. About 2 to $23 \%$ of patients treated by anti-tuberculosis drugs experience an exacerbation of their initial clinical symptoms and / or the appearance of a new active infectious site $[6,10]$. This phenomenon known as a "paradoxical" reaction, is defined as an aggravation of existing lesions or presentation of new lesions during anti-tuberculosis treatment [6]. It is rare in immunocompetents and exceptionally revealed by signs of digestive impairment $[10,11]$.

Our patient was immunocompetent and presented a paradoxical reaction that was acute bowel obstruction during anti-tuberculosis treatment for bacteriologically positive pulmonary tuberculosis. Brown CS et al. observed $14.4 \%$ frequency of paradoxical reactions in immunocompromised patients against $3.8 \%$ in immunocompetent patients [10]; this explains low occurrence of paradoxical reactions in immunocompetent patients.

Our case was of a 56 years old, male patient of african descent; no difference was observed in frequency of occurrence of paradoxical reactions according to ethnicity, although the infected site is more likely to be pulmonary in african and caucasian ethnic group and lymph node in asians in Brown et al. series [10].

Time limit of the paradoxical reaction in our case was 5 weeks. Rakotoarivelo et al. found a similar delay ( 5.5 weeks) in their series [13]; it should be noted that there was no gastrointestinal paradoxical reaction in this series [13]. Shinga et al. Observed an onset of acute bowel obstruction after 4 weeks of antituberculosis treatment [12]; Cheng VCC et al. on the other hand, obtained a longer mean delay of 8.5 weeks [5].

Clinical symptoms in our case were typical of acute bowel obstruction in accordance to the clinical signs described by Mondor, abdominal pain, vomiting, gas and faecal matter obstruction and abdominal meteorism. Shinga et al. in Dakar had a similar clinical case [12]. Plain abdominal x-ray film showed hydroaeric images that were wider than high (image) suggesting ileum involvement. Shinga et al. had similar findings on an abdominal $\mathrm{x}$-ray with confirmed by computed tomography [12]. Chong V H et al. Described gastrointestinal tuberculosis sites; the most frequent site was ileocecal (38\%) followed by ascending colon $(23.8 \%)$ and appendix (19\%) [3]. The ileal site in our case and that of Shinga et al. [12] represents only $9.5 \%$ of Chong V H et al. Cases [3].

Chaabane et al. describe 4 macroscopic forms of intestinal tuberculosis lesions: ulcerative form which is frequent in immunocompromised host, hypertrophic form encountered more in immunocompetents hosts, stenosing form more often ileal and ulcerative hypertrophic form which can mimic digestive neoplasia [9]. In our case, the macroscopic appearance of the intestinal lesions was of hypertrophic form with ileal and omental thickening (image 2). Shinga et al. had a similar aspect [12]. Microscopic aspect in our case showed a eosinophilic necrosis surrounded by numerous epithelioid cells without notable granulomas suggestive of tuberculosis (image 3); Shinga et al. found a Langhans-type giant cell granuloma with central caseous necrosis [12] well suggestive of tuberculosis.

The surgical procedure performed was section of adhesion to restore intestinal transit, rincing and drainage of the peritoneal cavity; intestinal tuberculosis treatment was medically done with anti-tuberculosis drugs taken on the 5th postoperative day. Postoperative period was uneventful under this treatment; the patient was declared cured after 6 months of anti-tuberculosis treatment identical to therapeutic regimen in a pulmonary tuberculosis patient; The Center for Disease Control (CDC) and the American Thoracic Society (ATS) agree on a therapeutic regimen identical to pulmonary tuberculosis, namely 6 months of treatment $(2 \mathrm{RHZE}+4 \mathrm{RH})[14,15]$. The same finding was reported by Lee et al. who described a paradoxical reaction revealed by intestinal sub-obstruction in an immunocompetent host at 3 months of antituberculosis for pulmonary tuberculosis. In this case, the patient had undergone digestive surgery and had progressed well under the same initial anti-tuberculosis treatment [11].

\section{CONCLUSION}

Paradoxical reaction such as acute bowel obstruction in an immunocompetent patient is rare; treatment is surgical to remove the intestinal obstruction, but mostly medical by a therapeutic regimen identical to that of pulmonary tuberculosis. Our patient underwent surgery and continued his antituberculosis treatment with a uneventful outcome.

\section{REFERENCES}

1. World Health Organization. (2020). Global Tuberculosis Report 2020. Accessed October 2020.

2. World Health Organization. (2018). Global Tuberculosis Report 2018. S. I. : World Health Organization. 
3. Chong, V. H., \& Lim, K. S. (2009). Gastrointestinal tuberculosis. Singapore Med J, 50(6), 638.

4. Choremis, C. B., Padiatellis, C., Zoumboulakis, D., \& Yannakos, D. (1955). Transitory exacerbation of fever and roentgenographic findings during treatment of tuberculosis in children. American Review of Tuberculosis and Pulmonary Diseases, 72(4), 527-536.

5. Cheng, V., Ho, P., Lee, R., Chan, K., Woo, P., Lau, S., \& Yuen, K. (2002). Clinical spectrum of paradoxical deterioration during antituberculosis therapy in non-HIV-infected patients. European Journal of Clinical Microbiology and Infectious Diseases, 21(11), 803-809.

6. Bell, L. C., Breen, R., Miller, R. F., Noursadeghi, M., \& Lipman, M. (2015). Paradoxical reactions and immune reconstitution inflammatory syndrome in tuberculosis. International journal of infectious diseases, 32, 39-45.

7. Programme National contre la Tuberculose du Bénin. (2019). Rapport annuel.

8. WHO. (2010). Treatment of tuberculosis: guidelines. $4^{\text {th }}$ ed, Genève. 2010. Google scholar

9. Chaabane, N. B., Mansour, W. B., Hellara, O., Melki, W., Loghmeri, H., Bdioui, F., ... \& Saffar, H. (2012). La tuberculose gastrointestinale. Hépato-Gastro \& Oncologie Digestive, 19(1), 28-35.

10. Brown, C. S., Smith, C. J., Breen, R. A. M., Ormerod, L. P., Mittal, R., Fisk, M., ... \& Lipman, M. C. I. (2016). Determinants of treatment-related paradoxical reactions during anti-tuberculosis therapy: a case control study. BMC infectious diseases, 16(1), 1-9.

11. Lee, C. W., Chang, W. H., Shih, S. C., Wang, T. E., Chang, C. W., Bair, M. J., ... \& Chen, Y. J. (2009). Gastrointestinal tract pseudo-obstruction or obstruction due to Mycobacterium tuberculosis breakthrough. International Journal of Infectious Diseases, 13(4), e185-e187.

12. Shinga, B. W., Dièye, A., Badiane, N. M. D., Lakhe, N. A., Diallo, V. M. P. C., Mbaye, K. D., ... \& Seydi, M. (2019). Tuberculose intestinale révélée par une occlusion intestinale aigüe au cours d'une réaction paradoxale au traitement antituberculeux chez un patient immunocompétent: à propos d'un cas et revue de la littérature. The Pan African Medical Journal, 32.

13. Rakotoarivelo, R. A., Vandenhende, M. A., Michaux, C., Morlat, P., \& Bonnet, F. (2013). Réactions paradoxales sous traitement antituberculeux chez des personnes non infectées par le VIH: quatre nouvelles observations et revue de la littérature. La Revue de médecine interne, 34(4), 202-208.

14. Dela Cruz, C. S., Lyons, P. G., Pasnick, S., Weinstock, T., Nahid, P., Wilson, K. C., \& Thomson, C. C. (2016). Treatment of drugsusceptible tuberculosis. Annals of the American Thoracic Society, 13(11), 2060-2063.

15. Jullien, S., Jain, S., Ryan, H., \& Ahuja, V. (2016). Six- month therapy for abdominal tuberculosis. Cochrane Database of Systematic Reviews, (11). 